\title{
A Soft Porous Crystal based upon Organic Cages that Exhibits Guest-Induced Breathing and Selective Gas Separation
}

Zhifang Wang, ${ }^{1,8}$ Nivedita Sikdar, ${ }^{2}$ Shi-Qiang Wang, ${ }^{2}$ Xia Li, ${ }^{1,8}$ Meihui Yu, ${ }^{7}$ Xian-He Bu, ${ }^{7}$ Ze Chang, ${ }^{7}$ Xiaolong Zou, ${ }^{3,6}$ Yao Chen,, ${ }^{4}$ Peng Cheng, ${ }^{1,8}$ Kuang Yu, ${ }^{* 3}$ Michael J. Zaworotko*2 and Zhenjie Zhang*1,4,8

${ }^{1}$ College of Chemistry, Nankai University, Tianjin, 300071, China.

2 Department of Chemical Sciences, Bernal Institute, University of Limerick, Limerick V94T9PX, Republic of Ireland.

${ }^{3}$ Center of Environmental Science and New Energy Technology, Tsinghua-Berkeley Shenzhen Institute, Tsinghua University, Shenzhen, 518055, China.

${ }^{4}$ State Key Laboratory of Medicinal Chemical biology, Nankai University, Tianjin 300071, China.

${ }^{5}$ College of Pharmacy, Nankai University, Tianjin, 300071, China.

6 Shenzhen Geim Graphene Center and Low-Dimensional Materials and Devices Laboratory, Tsinghua-Berkeley Shenzhen Institute (TBSI), Tsinghua University, Shenzhen 518055, China.

${ }^{7}$ School of Materials Science and Engineering, Nankai University, Tianjin, 300071, China.

${ }^{8}$ Key Laboratory of Advanced Energy Materials Chemistry (MOE), Nankai University, Tianjin 300071, China

Dedicated to the 100th anniversary of Nankai University 
General: All reagents were purchased from commercial sources and used without further treatments. ${ }^{1} \mathrm{H}$ NMR spectra was recorded on Bruker AV400 instruments at $400 \mathrm{MHz}$. Chemical shifts were reported in parts per million (ppm) down field from internal tetramethylsilane. Powder X-ray diffraction measurements were recorded on a D/Max-2500 $\mathrm{X}$-ray diffractometer using $\mathrm{Cu}-\mathrm{K} \alpha$ radiation by depositing powder on glass substrate, $2 \theta$ from $3^{\circ}$ to $40^{\circ}$ with $0.02^{\circ}$ increment. The absorption of gas $\left(\mathrm{C}_{3} \mathrm{H}_{4} 、 \mathrm{C}_{3} \mathrm{H}_{6} 、 \mathrm{C}_{3} \mathrm{H}_{8} 、 \mathrm{CO}_{2}\right.$ and $\left.\mathrm{N}_{2}\right)$ were screened using a Micromeritics ASAP-2020. High-pressure gas adsorption isotherms were performed using the Particulate Systems HPVA-II 100 at Micromeritics Instrument Corporation, a static volumetric system, connected to a high vacuum source. Fourier transform infrared spectra (FT-IR) spectra were recorded on a Nicolet iS 50 ATR-FTIR instrument. Scanning electron microscopy (SEM) images were taken with Hitachi JSM-7500F scanning electron microscopy. In situ adsorption coupled with X-ray diffraction measurements were recorded on a Rigaku Smart Lab 3kw, and the measurements temperature was maintained by Anton Paar TTK 600 accessory.

\section{Dynamic gas breakthrough measurement experiments}

In typical breakthrough experiments, $\sim 0.56 \mathrm{~g}$ of pre-activated NKPOC-1- $\boldsymbol{\alpha}$ was placed in quartz tubing ( $8 \mathrm{~mm}$ diameter) to form fixed bed. First, the adsorbent bed was purged under a $30 \mathrm{~cm}^{3} \mathrm{~min}^{-1}$ flow of $\mathrm{He}$ gas at $60{ }^{\circ} \mathrm{C}$ for $60 \mathrm{~min}$ prior to breakthrough experiment. Upon cooling to room temperature, the gas flow was switched to the desired gas mixtures at a particular flow rate (the respective flow rates are mentioned in the main manuscript). Herein, binary $\left(2: 1 \mathrm{C}_{3} \mathrm{H}_{4} / \mathrm{C}_{3} \mathrm{H}_{6}\right.$ and $\left.\mathrm{C}_{3} \mathrm{H}_{4} / \mathrm{C}_{3} \mathrm{H}_{8}\right)$ and ternary $\left(2: 1: 1 \mathrm{C}_{3} \mathrm{H}_{4} / \mathrm{C}_{3} \mathrm{H}_{6} / \mathrm{C}_{3} \mathrm{H}_{8}\right)$ C3-hydrocarbon mixtures were performed for breakthrough experiments at $25{ }^{\circ} \mathrm{C}$ and 1 bar. The outlet composition was continuously monitored by a gas chromatography (Shimadzu GC2030 with a FID detector) until complete breakthrough was achieved. After each breakthrough experiment, the packed column bed was regenerated at $120^{\circ} \mathrm{C}$ with constant $\mathrm{He}$ flow $\left(30 \mathrm{~cm}^{3} \mathrm{~min}^{-1}\right)$ for $\sim 120$ min to ensure complete sample regeneration. The total gas flow rates of $\mathrm{C}_{3} \mathrm{H}_{4} / \mathrm{C}_{3} \mathrm{H}_{6}$, $\mathrm{C}_{3} \mathrm{H}_{4} / \mathrm{C}_{3} \mathrm{H}_{8}$ and $\mathrm{C}_{3} \mathrm{H}_{4} / \mathrm{C}_{3} \mathrm{H}_{6} / \mathrm{C}_{3} \mathrm{H}_{8}$ are $0.95,1.1$ and $1.0 \mathrm{~mL} / \mathrm{min}$, respectively. 


\section{Single crystal X-ray crystallography}

Single crystals of NKPOC-1- $\boldsymbol{\alpha}(0.2 \mathrm{~mm} \times 0.2 \mathrm{~mm} \times 0.05 \mathrm{~mm})$ and NKPOC-1- $\boldsymbol{\beta}(0.2 \mathrm{~mm} \times$ $0.2 \mathrm{~mm} \times 0.05 \mathrm{~mm}$ ) were collected at $120 \mathrm{~K}$ on an Oxford SuperNova diffractometer equipped with graphite monochromated Mo-Ka radiation $(\lambda=0.71073 \AA)$. The structures were solved by the direct method and refined by the full-matrix least-squares method on F2 with anisotropic thermal parameters for all non-hydrogen atoms. We used the 'squeeze' of PLATON to remove the disordered solvent molecules of NKPOC-1- $\boldsymbol{\beta}$, the SQUEEZE command was not performed for NKPOC-1- $\alpha$. Crystallographic data and structure refinement data are shown in Table S3. The crystal data files of NKPOC-1- $\boldsymbol{\alpha}$ and NKPOC-1- $\boldsymbol{\beta}$ were deposited into the Cambridge Crystallographic Data Centre (CCDC) and assigned numbers 1904744 and 1904745, respectively.

\section{The single component gas adsorption test}

The prepared sample of NKPOC-1 and NKPOC-1- $\boldsymbol{\alpha}$ were evacuated with vacuuming under heating at $120{ }^{\circ} \mathrm{C}$ for at least $10 \mathrm{~h}$ before the analysis was started. The measurement temperatures were maintained at $195 \mathrm{~K}, 253 \mathrm{~K}, 273 \mathrm{~K}, 298 \mathrm{~K}, 313 \mathrm{~K}$ using a bath of dry ice/isopropanol slurry, ice/methanol, ice/water mixture, and a water bath, respectively. After the gas adsorption test was completed, it was necessary to be evacuated on a vacuum pump for $5 \mathrm{~h}$ at room temperature until the pressure is close to $30 \mathrm{mmHg}$ to ensure the adsorbate can be completely removed before the next test.

\section{Enthalpy of gate opening}

The Clausius-Clapeyron equation was used to calculate the molar enthalpy of gate opening $\left(\triangle H_{G O}\right)$.

$d \ln P_{G O} /(d(1 / \mathrm{T}))=\Delta H_{G O} / R$

$P_{G O}$ is gate opening pressure, $T$ is measurement temperature, $\mathrm{R}$ is gas constant.

\section{Numerical details}


All the molecular dynamics (MD) simulations were performed using Gromacs 5.1.4 program, ${ }^{1}$ with a modified version of OPLS-AA force field (see FORCE FIELD PARAMETERS section for details). ${ }^{2-8}$ We use Langevin stochastic dynamics for the temperature coupling, in conjunction with the Parrinello-Rahman barostat. Experimentally, the NKPOC-1 crystal stays in monoclinic structure before and after gas loading, thus we keep both $\alpha$ and $\gamma$ to be $90^{\circ}$ in all the simulations, while all other lattice parameters are fully relaxed. The coupling time for thermostat and barostat are 2.0 and $5.0 \mathrm{ps}$, respectively, and the compressibility is set to be 1.0e-5 bar $^{-1}$ in all dimensions. Particle Meshed Ewald (PME) is employed to describe the electrostatic interactions, and the Lennard-Jones potential is gradually switched off between 0.9-1.0 nm. All simulations are done with $1.0 \mathrm{fs}$ time step, and all crystal simulations are performed using a $2 \times 2 \times 2$ supercell containing 32 NKPOC-1 molecules.

To parameterize the force field (vide infra), we need to compute the crystallization energy and the single-cage conformation energies. All these benchmark data are obtained using VASP

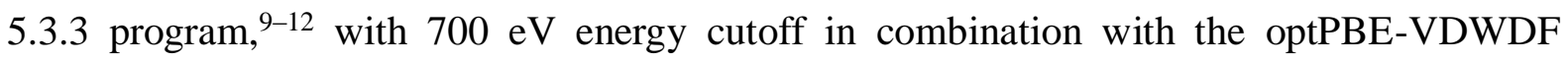
density functional. ${ }^{13}$ For all DFT calculations, PAW method is employed, and only the gamma point in the reciprocal space is sampled since we are studying weak interacting molecular crystals.

In order to study the sorption-induced phase transitions into more details, we perform crystal simulations starting from the SCXRD structure of NKPOC-1- $\alpha$. MD simulation reproduces all the experimental lattice parameters of NKPOC-1- $\boldsymbol{\alpha}$ within $3 \%$ of error, except for a slight overestimation for the $\beta$ angle $\left(111^{\circ} v s .103^{\circ}\right)$. This validates our force field and provides a good starting point for further adsorption studies.

Starting from this activated structure, we adopt a "greedy algorithm" to determine the positions of the adsorbed molecules: each time, we try to randomly insert around 10 gas molecules into existing apertures, followed by $1 \mathrm{~ns}$ NPT simulation to determine its energy. At each step, we perform 20 such trials, then pick the one with the lowest energy to be the starting geometry for further insertions. Our greedy algorithm serves as an approximation to mimic the non-ergodic (as indicated by the hysteresis) experimental adsorption process, in which each 
molecule is assumed to be adsorbed in sequence. In the following discussions, we will first investigate the $\mathrm{C} 3$ hydrocarbons results, and then $\mathrm{CO}_{2}$, which is slightly more complicated.

\section{Experiment section}

Synthesis and Characterization of NKPOC-1. N,N-bis(2-aminoethyl)ethylenediamine (10 mmol) and [5,5'-biisobenzofuran]-1,1',3,3'-tetraone (15 mmol) were refluxed in acetic acid $(120 \mathrm{~mL})$ for $24 \mathrm{~h}$ under Ar atmosphere. The solvent was removed under vacuum and the obtained residues were washed with dichloromethane to dissolve the organic cage molecules. Polymeric material was removed from the dichloromethane extract by filtration. The filtrate was concentrated and purified by flash column chromatography over silica gel $\left(\mathrm{CH}_{2} \mathrm{Cl}_{2} / \mathrm{CH}_{3} \mathrm{CH}_{2} \mathrm{CO}_{2} \mathrm{CH}_{3}, 5-15 \% \mathrm{CH}_{3} \mathrm{CH}_{2} \mathrm{CO}_{2} \mathrm{CH}_{3}\right)$ to afford pure NKPOC-1 in $6 \%$ yield as white solid. ${ }^{1} \mathrm{H}$ NMR $\left(400 \mathrm{MHz}, \mathrm{CDCl}_{3}\right) \delta 8.07(\mathrm{~d}, J=7.7 \mathrm{~Hz}, 6 \mathrm{H}), 7.47(\mathrm{~d}, J=7.7 \mathrm{~Hz}, 6 \mathrm{H})$, $6.35(\mathrm{~s}, 6 \mathrm{H}), 3.87$ (d, $J=66.2 \mathrm{~Hz}, 18 \mathrm{H}), 1.94(\mathrm{~s}, 6 \mathrm{H}) \mathrm{ppm} .{ }^{13} \mathrm{C} \mathrm{NMR}\left(101 \mathrm{MHz}, \mathrm{CDCl}_{3}\right): \delta$ 167.77, 167.26, 144.16, 134.04, 132.67, 132.60, 123.53, 119.22, 52.47, 33.87 ppm. MS (m/z): calcd for $[\mathrm{M}+\mathrm{H}]^{+}=1067.3000$. found:1067.2991

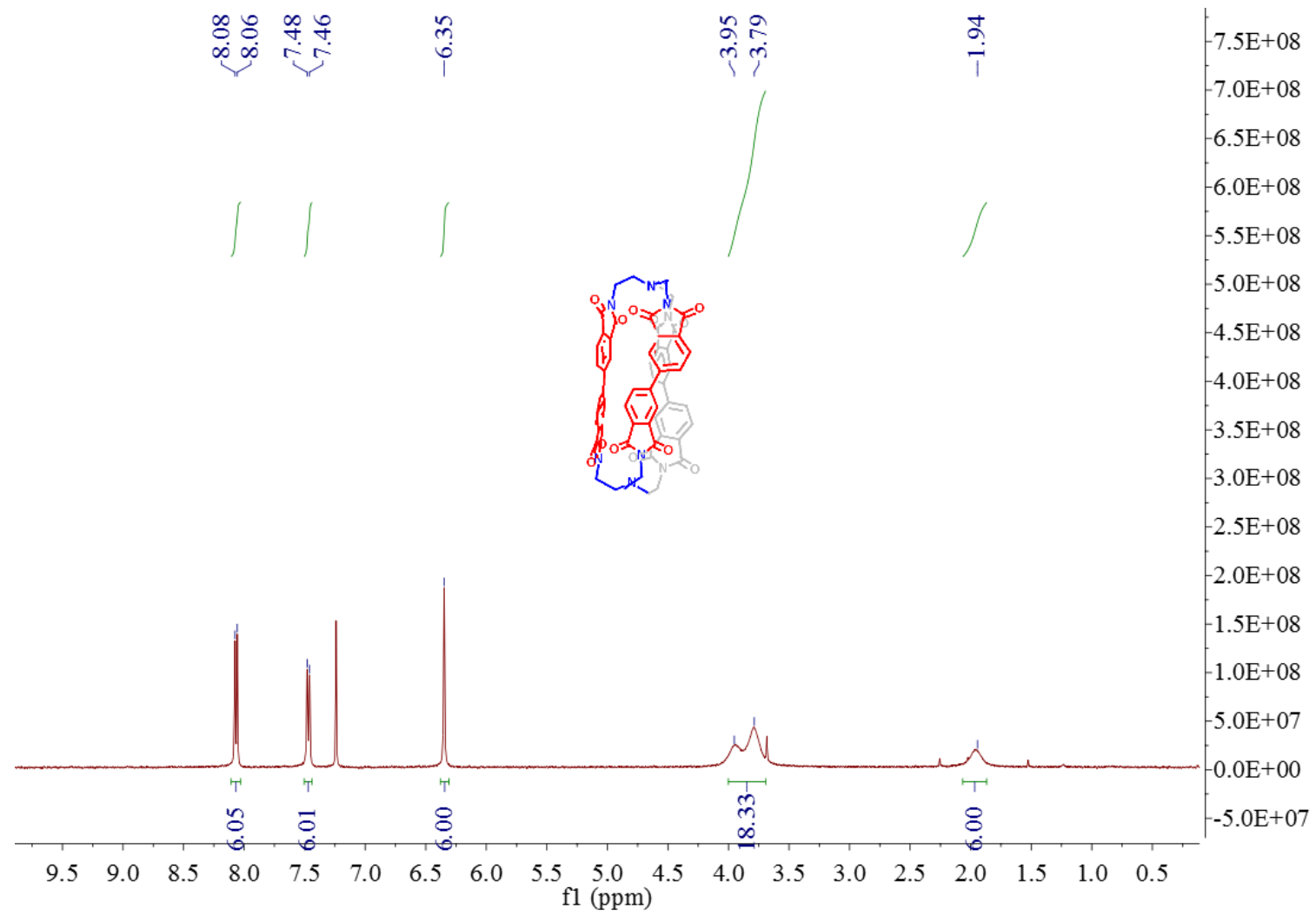

Figure S1. ${ }^{1} \mathrm{H}$ NMR data of NKPOC-1. 


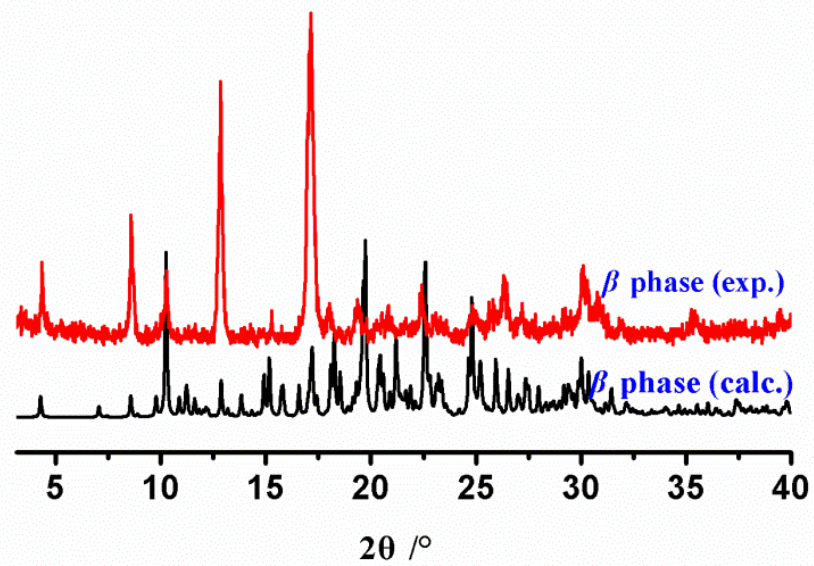

Figure S2. Comparison of experimental PXRD pattern recorded for NKPOC-1- $\boldsymbol{\beta}$ with calculated PXRD pattern derived from the single crystal structure.

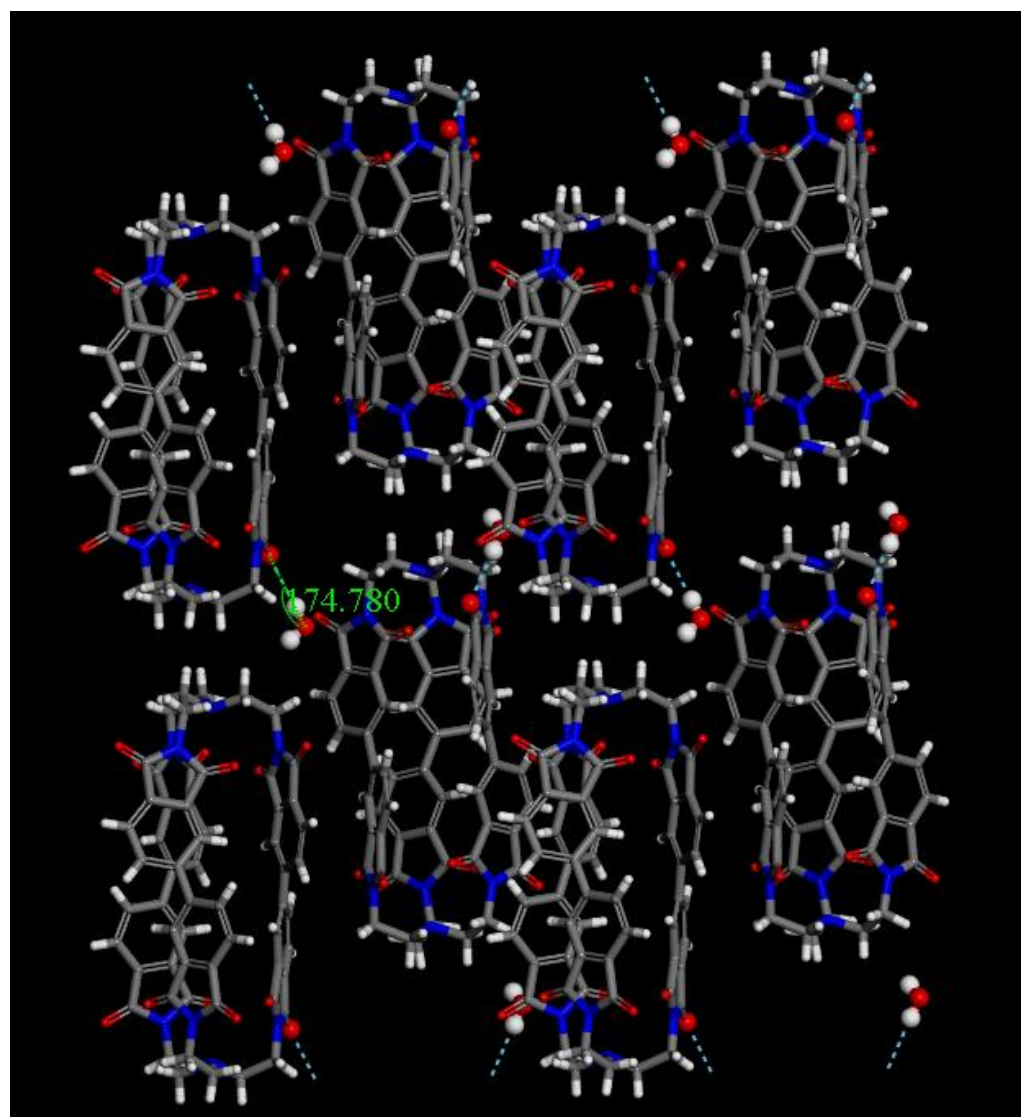

Figure S3. Crystal structure of the close-packed NKPOC-1- $\boldsymbol{\alpha}$ phase with some water molecules located in the pore. 


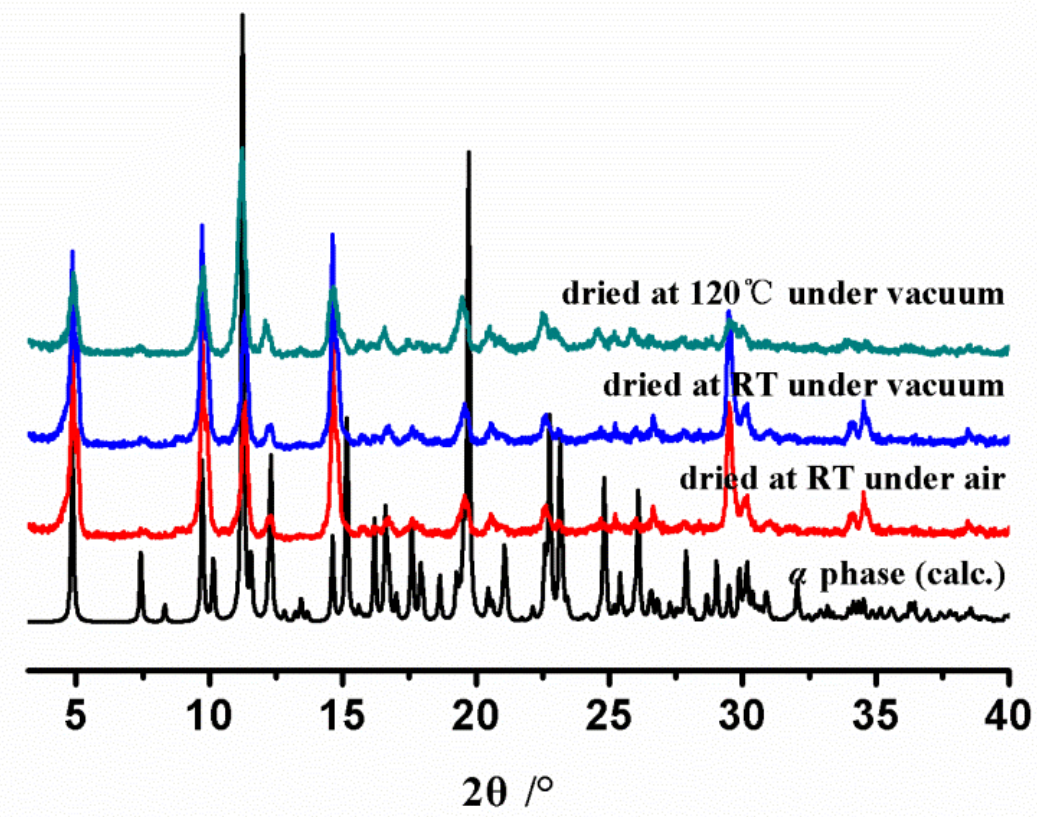

Figure S4. PXRD patterns of NKPOC-1- $\boldsymbol{\alpha}$ under different conditions.

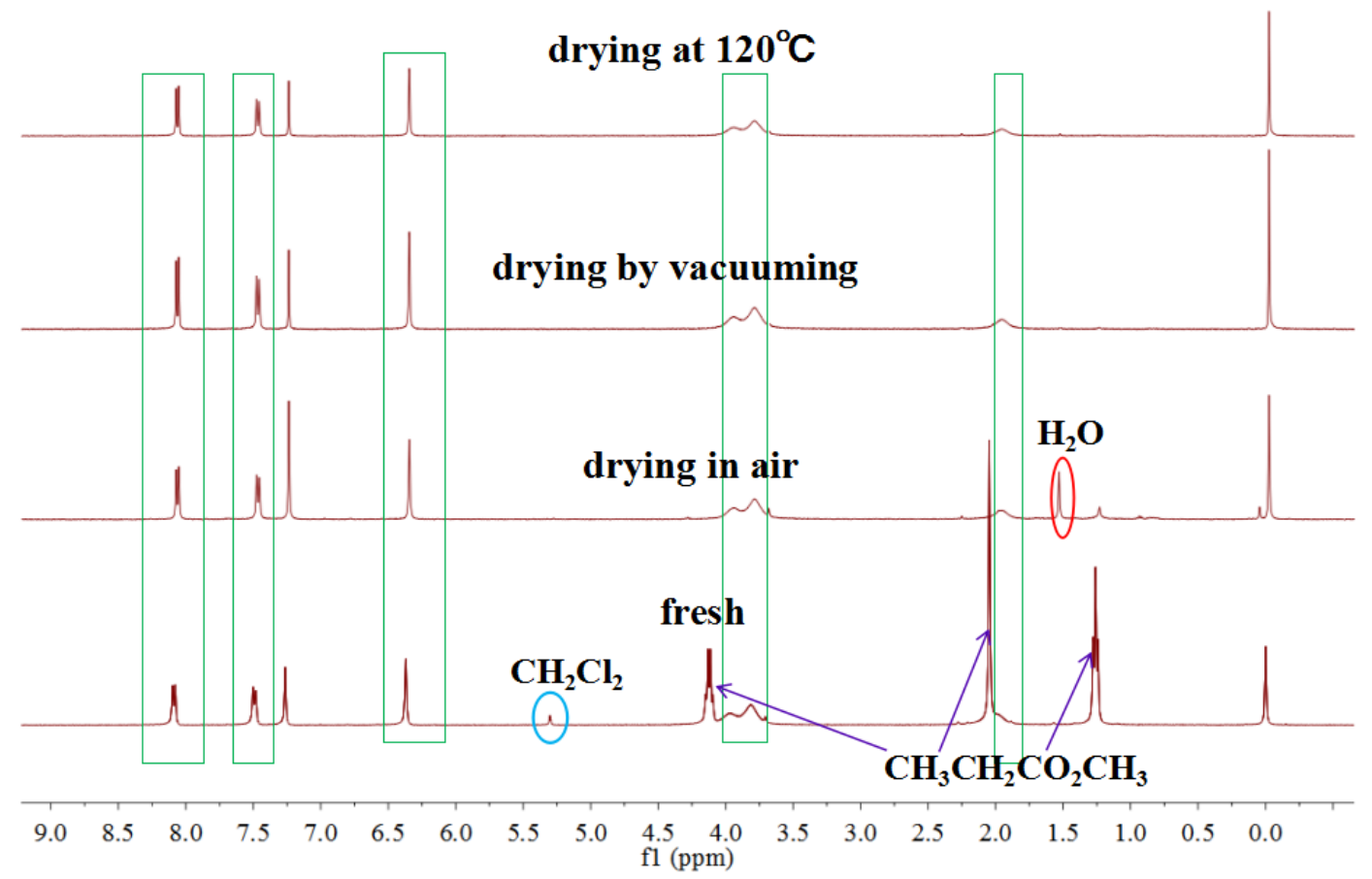

Figure S5. ${ }^{1} \mathrm{H}$ NMR data $\left(\right.$ solvent $\left.=\mathrm{CDCl}_{3}\right)$ for NKPOC-1- $\boldsymbol{\alpha}$ sample obtained via different drying method. 


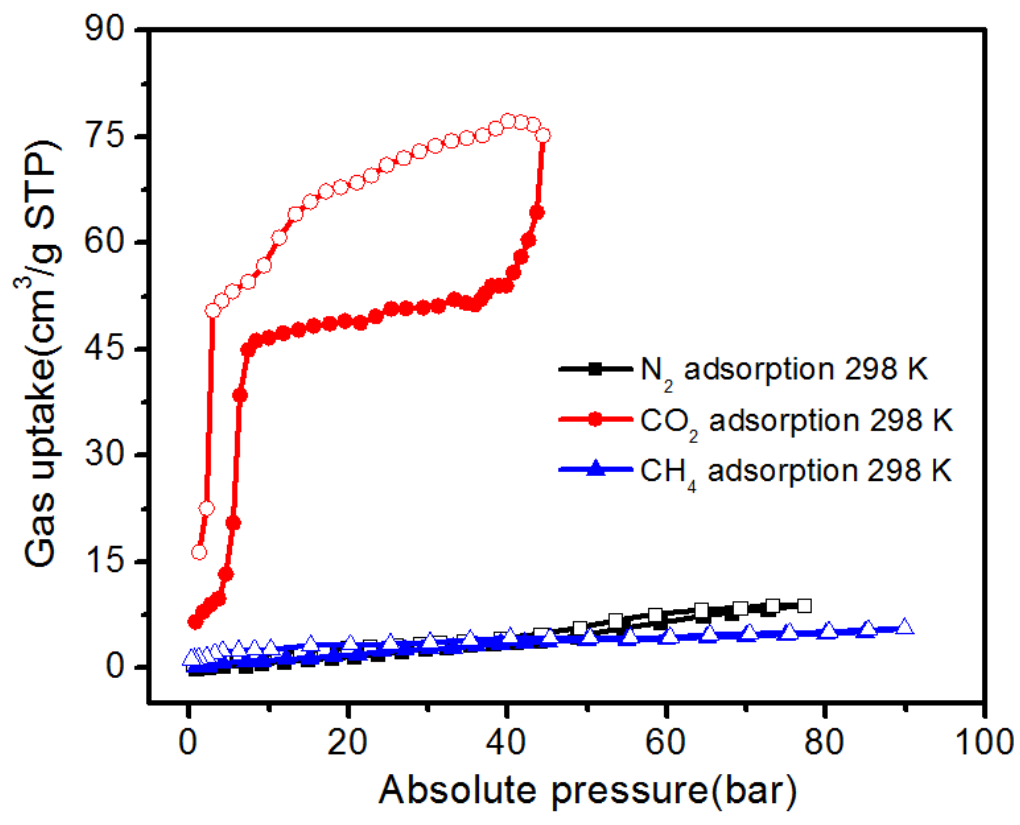

Figure S6. High-pressure gas sorption isotherms of NKPOC-1- $\alpha$ at $298 \mathrm{~K}$. The highest $\mathrm{CO}_{2}$ testing pressure was 44 bar because the maximum pressure of $\mathrm{CO}_{2}$ tank was 45 bar. Based on the sorption data of methane at high pressure of 90 bar at $298 \mathrm{~K}$, NKPOC-1- $\boldsymbol{\alpha}$ did not sorb significant amount of methane.
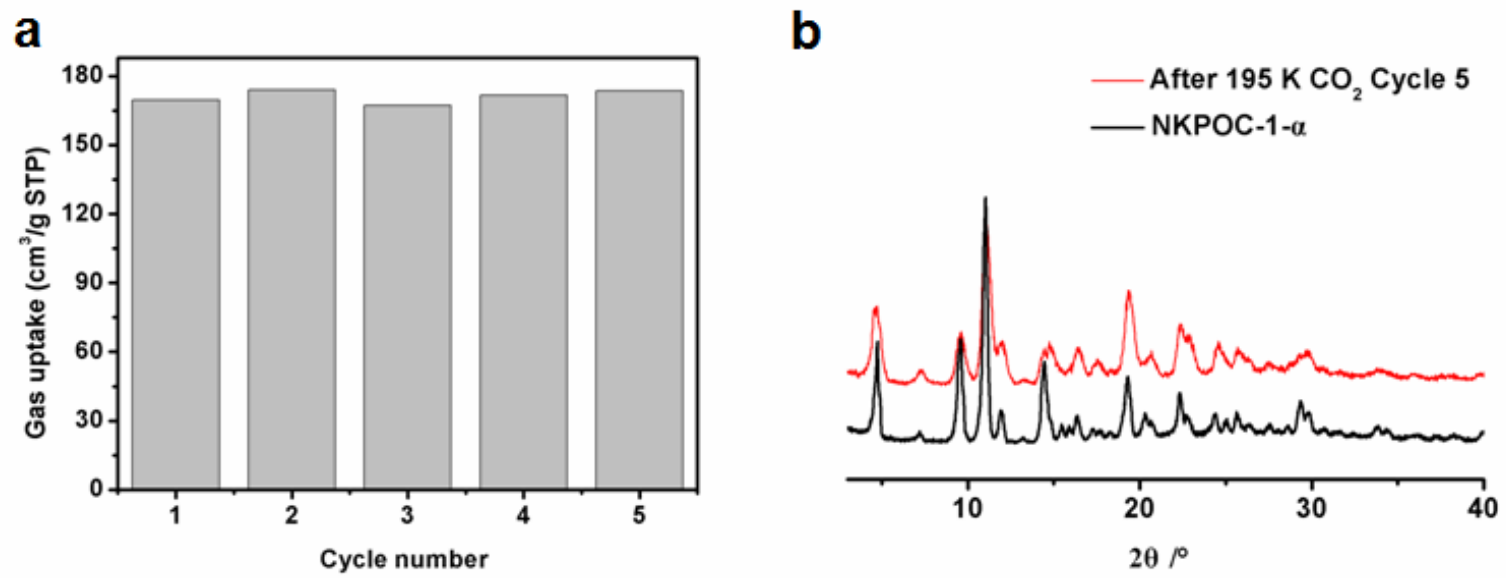

Figure S7. (a) $\mathrm{CO}_{2}$ uptake of NKPOC-1- $\alpha$ at $195 \mathrm{~K}$ and $\mathrm{P} / \mathrm{P}_{0}=0.95$ for five consecutive cycles. (b) PXRD patterns of activated NKPOC-1- $\alpha$ and after test five consecutive cycles of $\mathrm{CO}_{2}$ at $195 \mathrm{~K}$. 

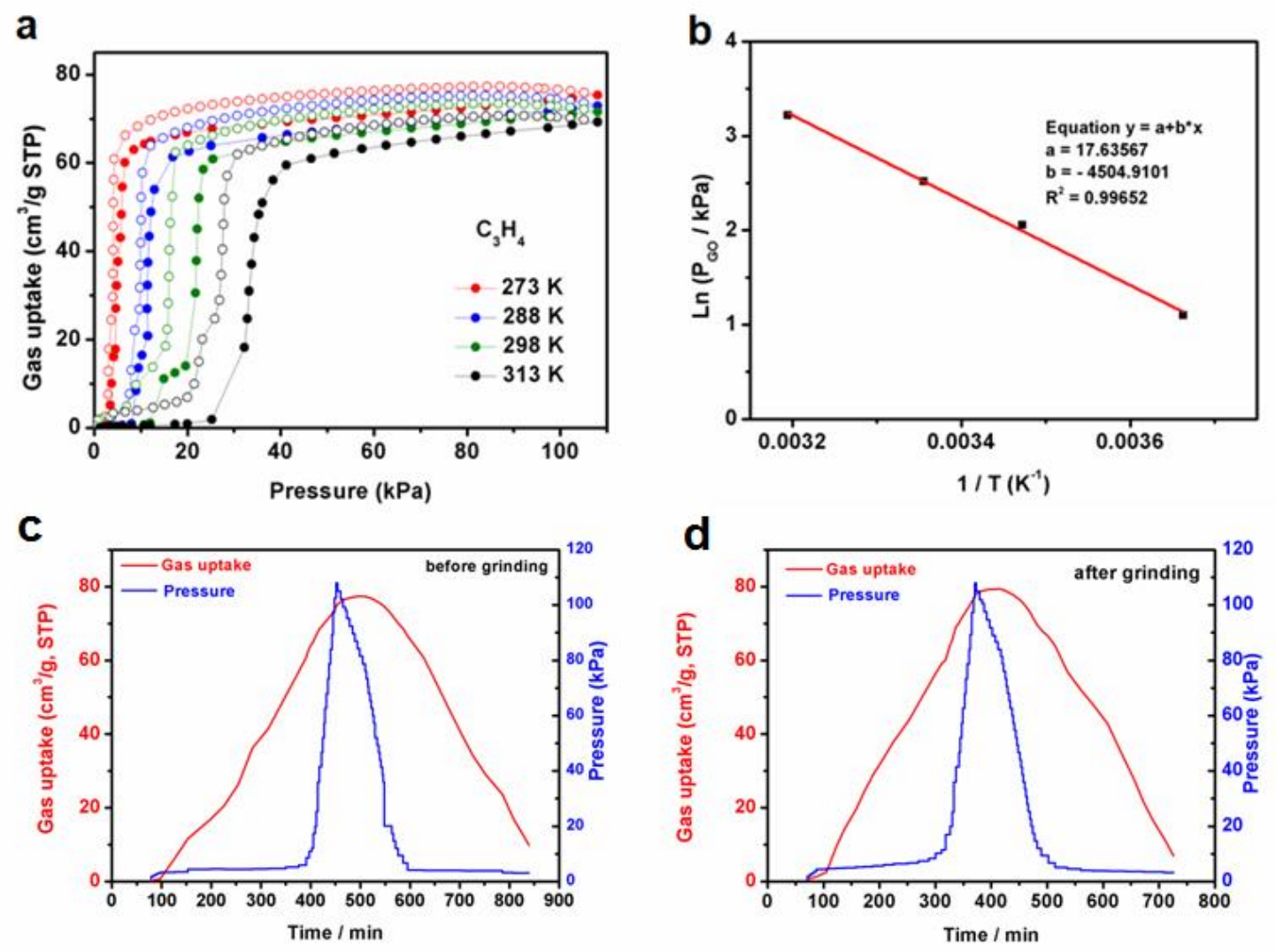

Figure S8. (a) Sorption isotherms of activated NKPOC-1- $\alpha$ at different temperature for $\mathrm{C}_{3} \mathrm{H}_{4}$. (b) Plot of gate opening pressure $\left(\mathrm{Ln} P_{G O}\right)$ vs inverse of measurement temperature $(1 / \mathrm{T})$ for adsorption isotherms of $\mathrm{C}_{3} \mathrm{H}_{4}$ measured at 273, 288, 298 and $313 \mathrm{~K}$. Depending on ClausiusClapeyron equation: $d \ln P_{G O} /(d(1 / \mathrm{T}))=\Delta H_{G O} / R$, we obtained a equation: $\left(\ln \mathrm{P}_{\mathrm{GO}}\right)=-4504.9 / \mathrm{T}$ + 17.63; Thus the enthalpy of gate opening $\Delta H$ is $37.5 \mathrm{~kJ} / \mathrm{mol}$. (c) The sorption kinetics data of unground NKPOC-1- $\boldsymbol{\alpha}$ crystals collected at $273 \mathrm{~K}$. (d) The sorption kinetics data of ground NKPOC-1- $\boldsymbol{\alpha}$ crystals collected at $273 \mathrm{~K}$. 


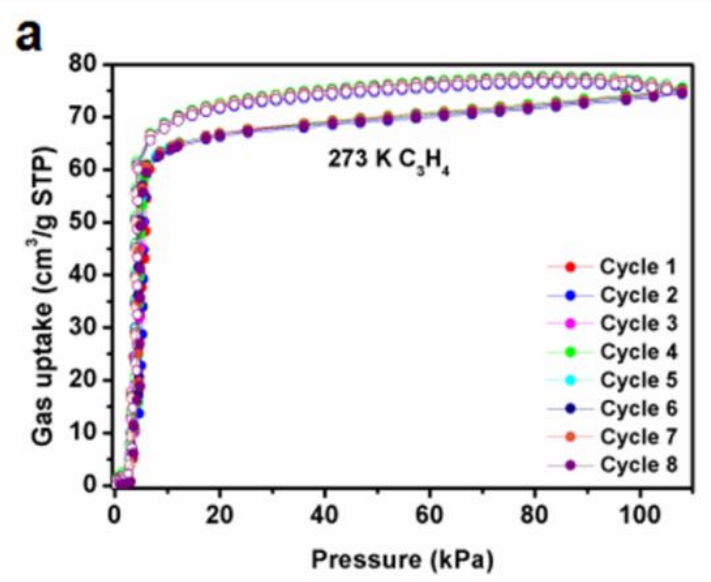

b

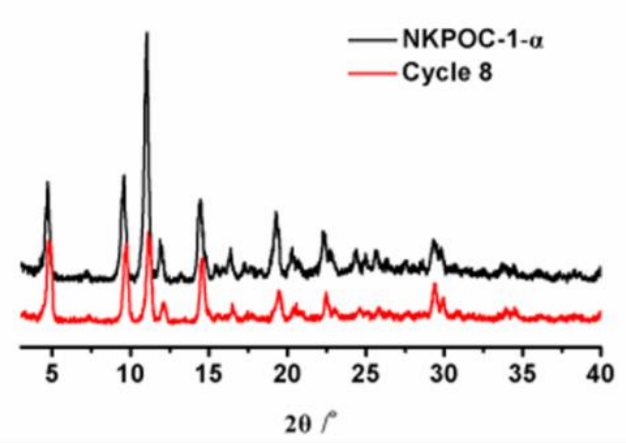

Figure S9. (a) Eight consecutive cycles of $\mathrm{C}_{3} \mathrm{H}_{4}$ sorption of activated NKPOC-1- $\boldsymbol{\alpha}$ at $273 \mathrm{~K}$. (b) PXRD patterns of activated NKPOC-1- $\boldsymbol{\alpha}$ before and after testing eight consecutive cycles of $\mathrm{C}_{3} \mathrm{H}_{4}$.

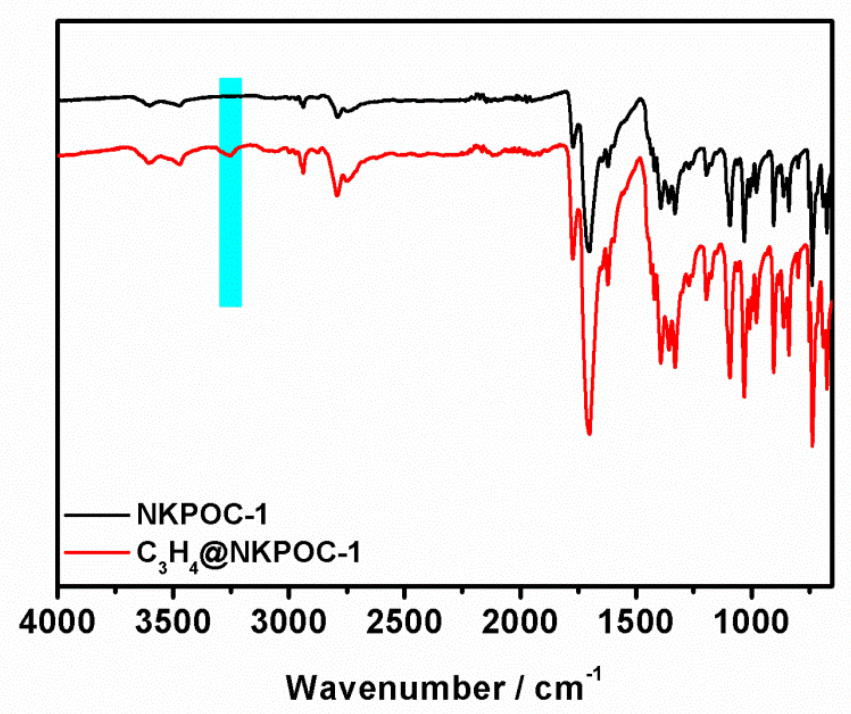

Figure S10. FT-IR spectra of $\mathbf{C}_{3} \mathbf{H}_{4} @$ @KPOC-1- $\boldsymbol{\alpha}$ at 298K, indicating the capture of $\mathrm{C}_{3} \mathrm{H}_{4}$ by. NKPOC-1- $\alpha$. 


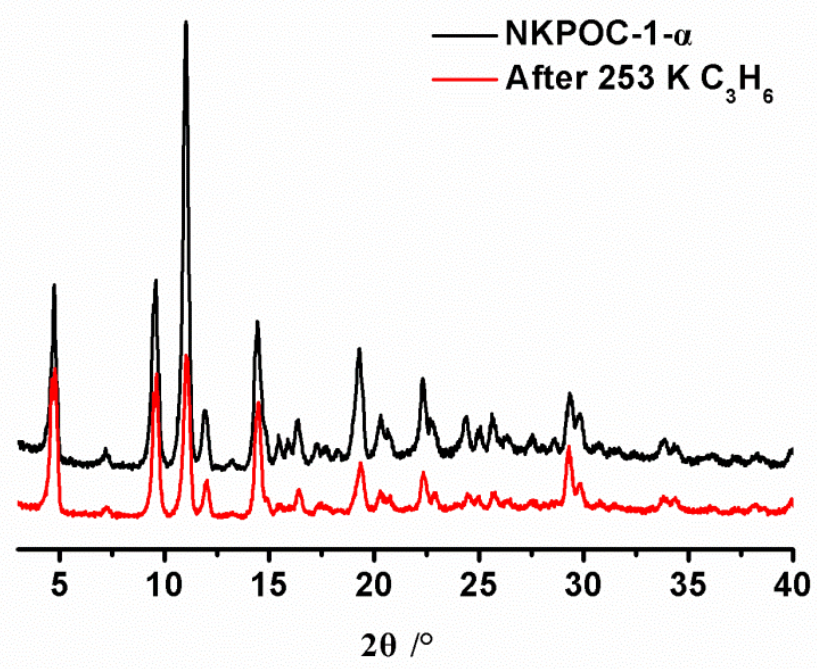

Figure S11. PXRD patterns of activated NKPOC-1- $\alpha$ before and after testing $\mathrm{C}_{3} \mathrm{H}_{6}$ sorption isotherms at $253 \mathrm{~K}$.

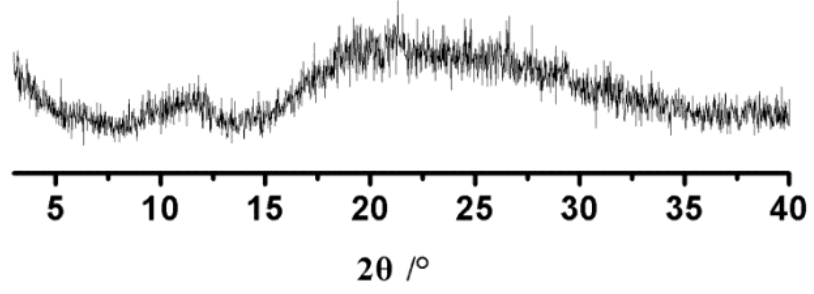

Figure S12. Powder X-ray diffraction patterns of amorphous NKPOC-1 produced by freeze-drying. 


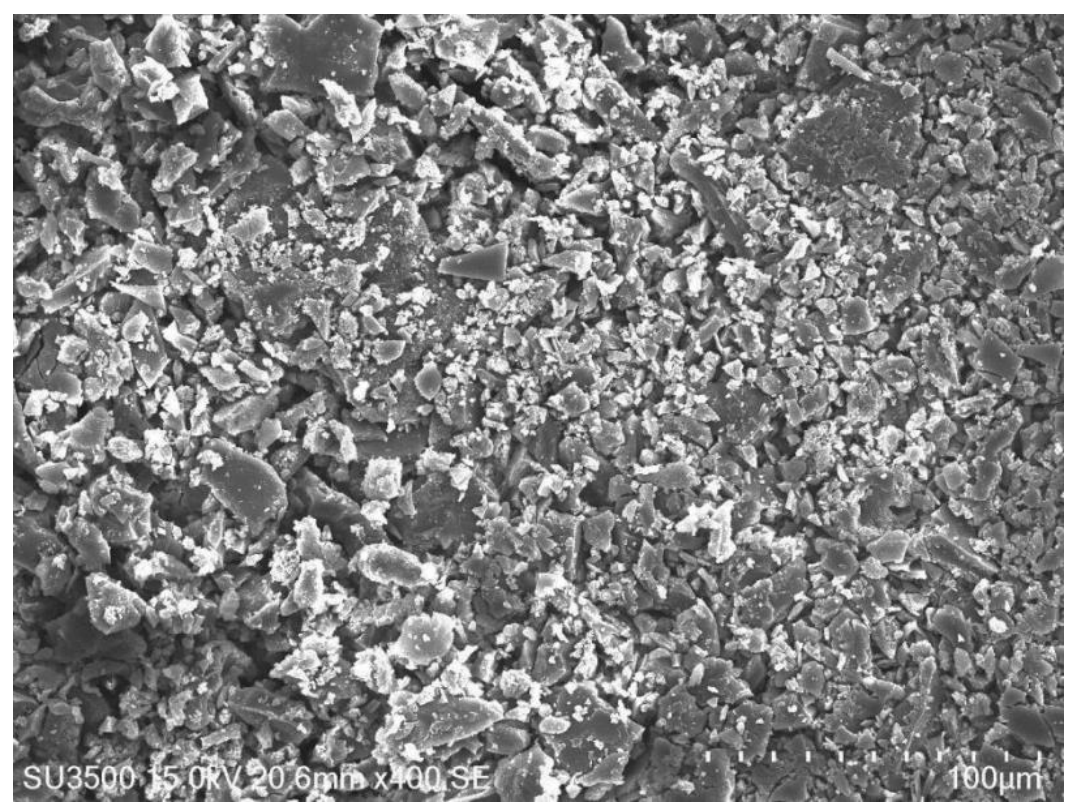

Figure S13. Scanning electron microscopy (SEM) images of prepared amorphous NKPOC-1 by freeze-drying.

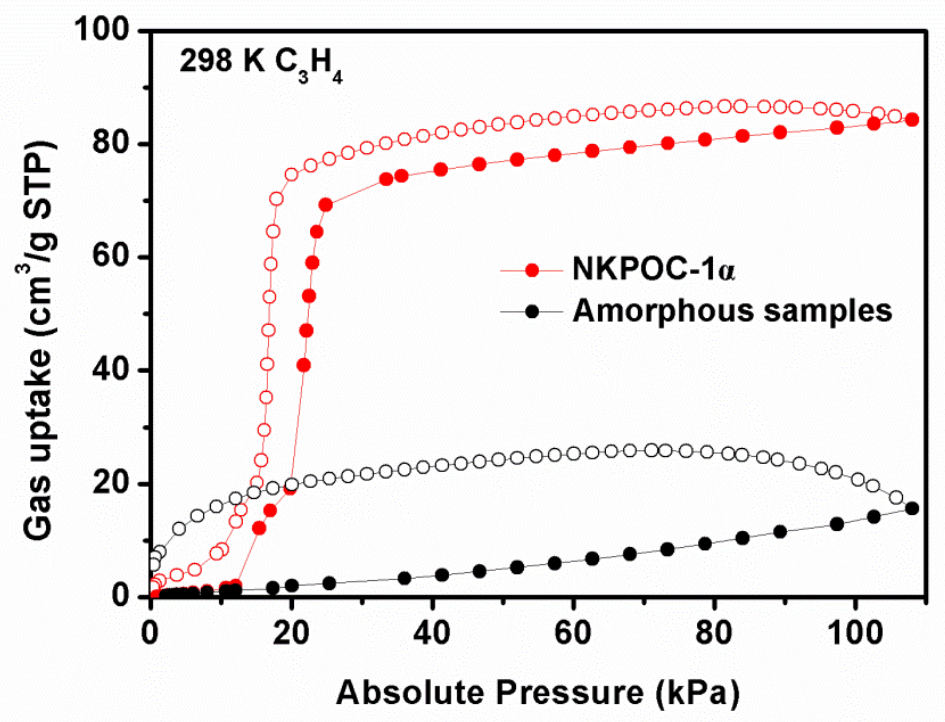

Figure S14. $\mathrm{C}_{3} \mathrm{H}_{4}$ sorption isotherms of amorphous NKPOC-1 (black) and NKPOC-1- $\alpha$ (red) at $298 \mathrm{~K}$. Notably, the amorphous samples showed a much lower $\mathrm{C}_{3} \mathrm{H}_{4}$ uptake of $15.6 \mathrm{~cm}^{3} / \mathrm{g}$ at 1 bar, as compared with an uptake of $84.2 \mathrm{~cm}^{3} / \mathrm{g}$ for the crystallized materials. Furthermore, the breathing behaviors completely disappeared in amorphous NKPOC-1 and further confirmed our hypothesis. 


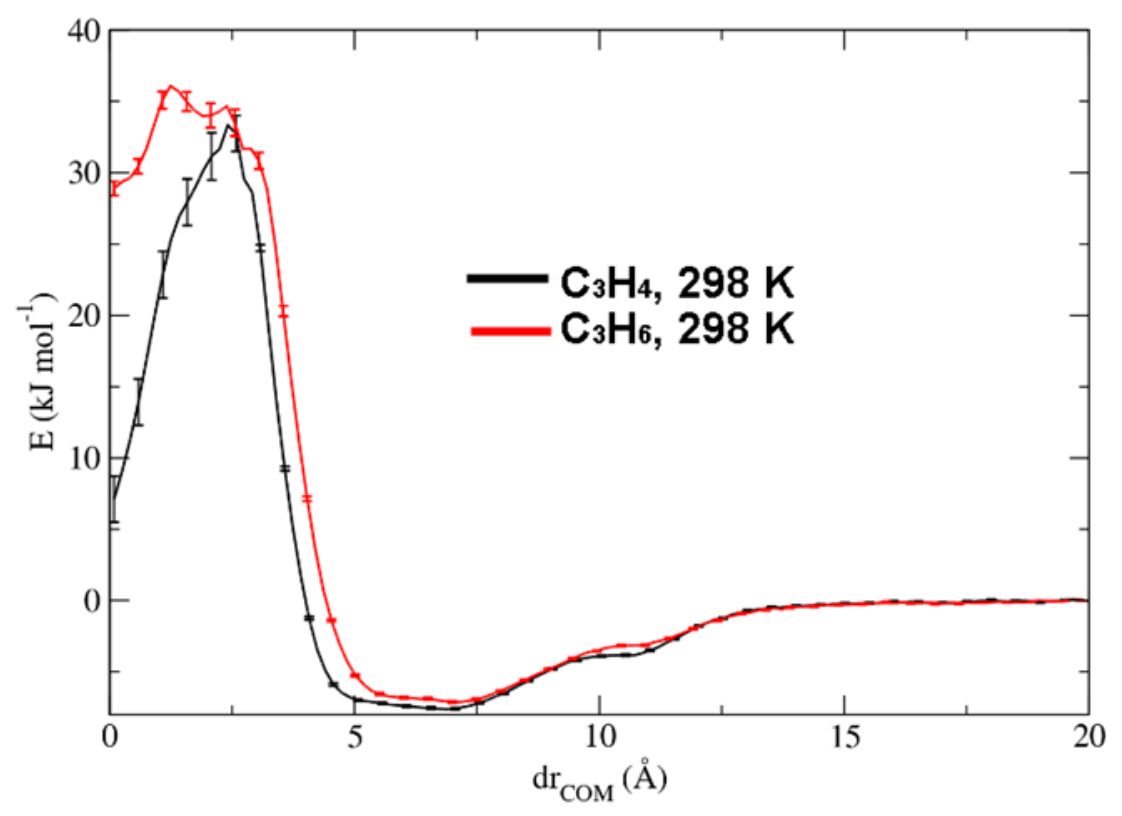

Figure S15. Free energy profile at $298 \mathrm{~K}$ for a single $\mathrm{C}_{3} \mathrm{H}_{4}$ and $\mathrm{C}_{3} \mathrm{H}_{6}$ molecule intercalated into a single NKPOC-1 cage. The $x$-axis is the distance between the centers of mass of the two molecules.

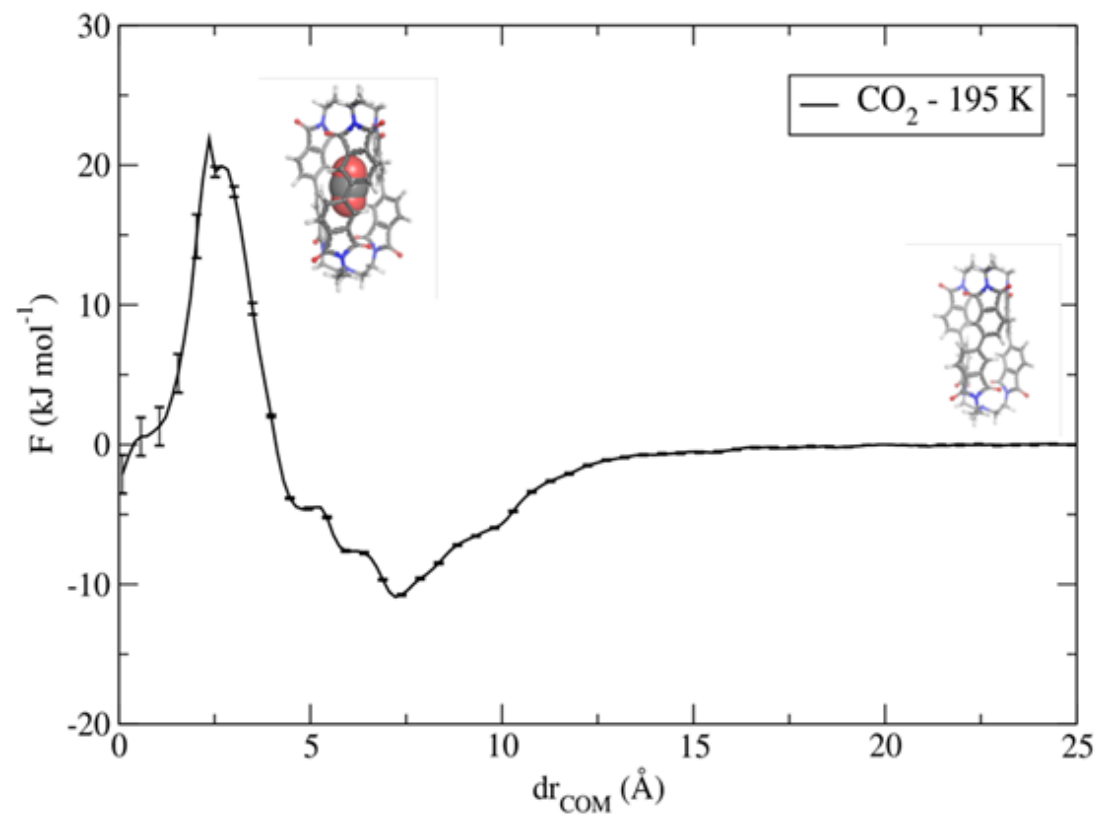

Figure S16. Free energy profile at $195 \mathrm{~K}$ for a $\mathrm{CO}_{2}$ molecule intercalated into a single NKPOC-1 cage. The $x$-axis is the distance between the centers of mass of the two molecules. 


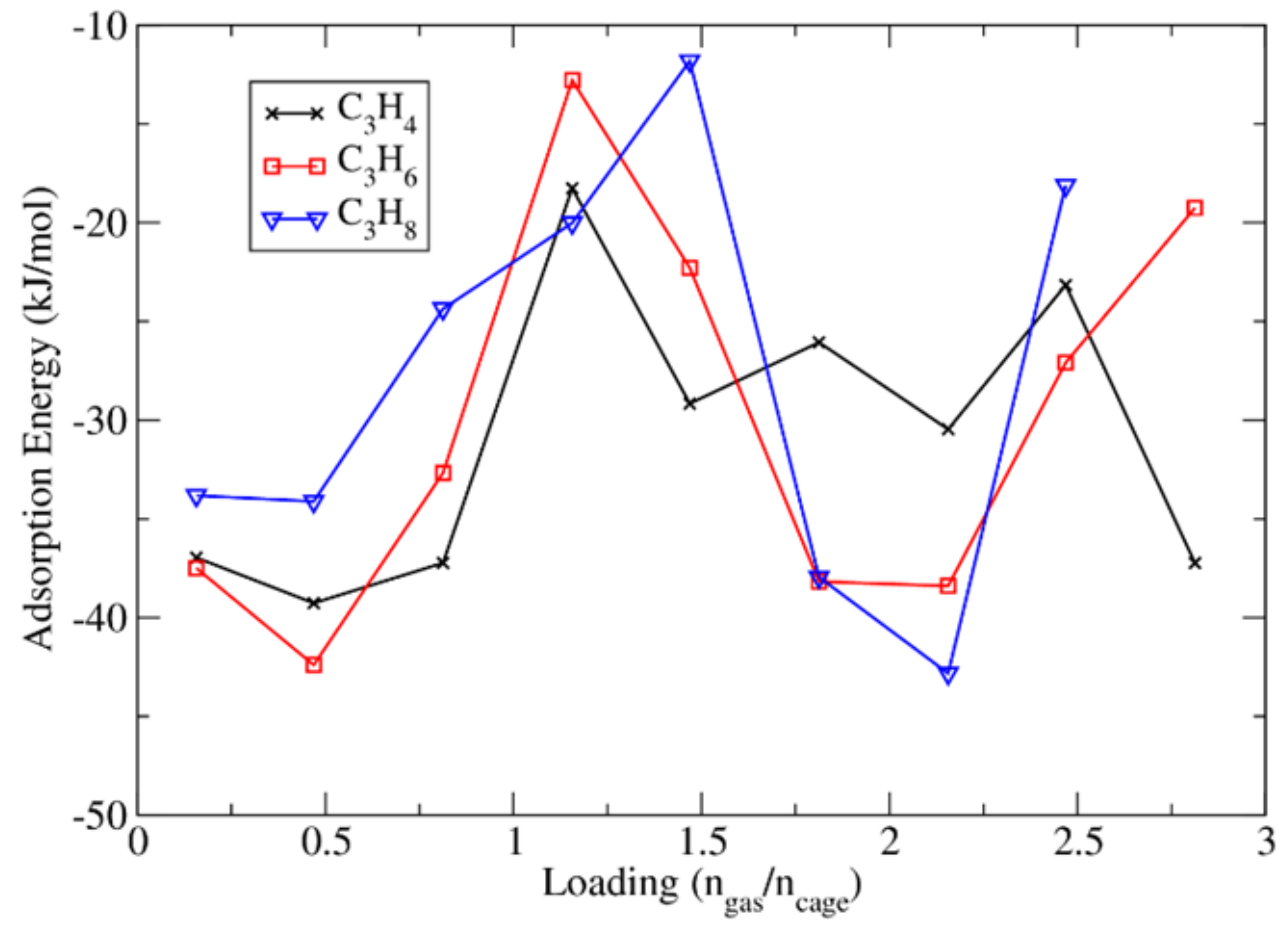

Figure S17. The adsorption energies at $253 \mathrm{~K}$, plotted against the loading amount.

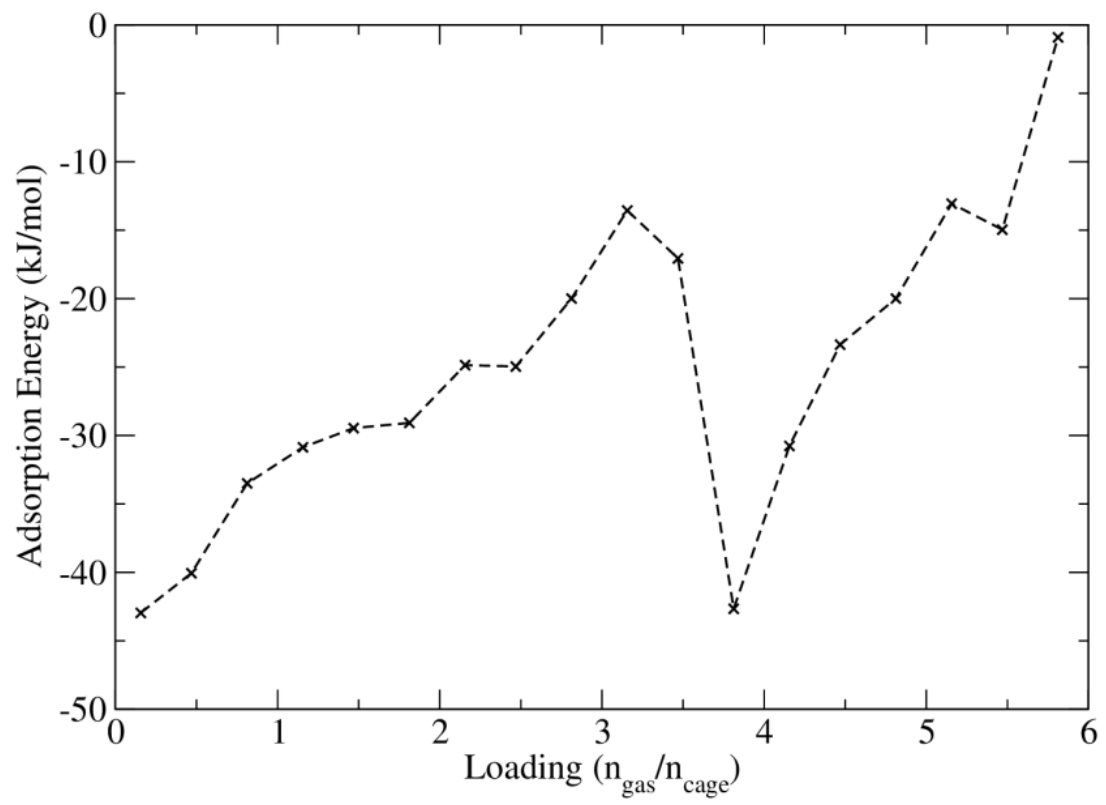

Figure S18. The adsorption energies of $\mathrm{CO}_{2}$ at $195 \mathrm{~K}$, plotted against the loading ratio. 


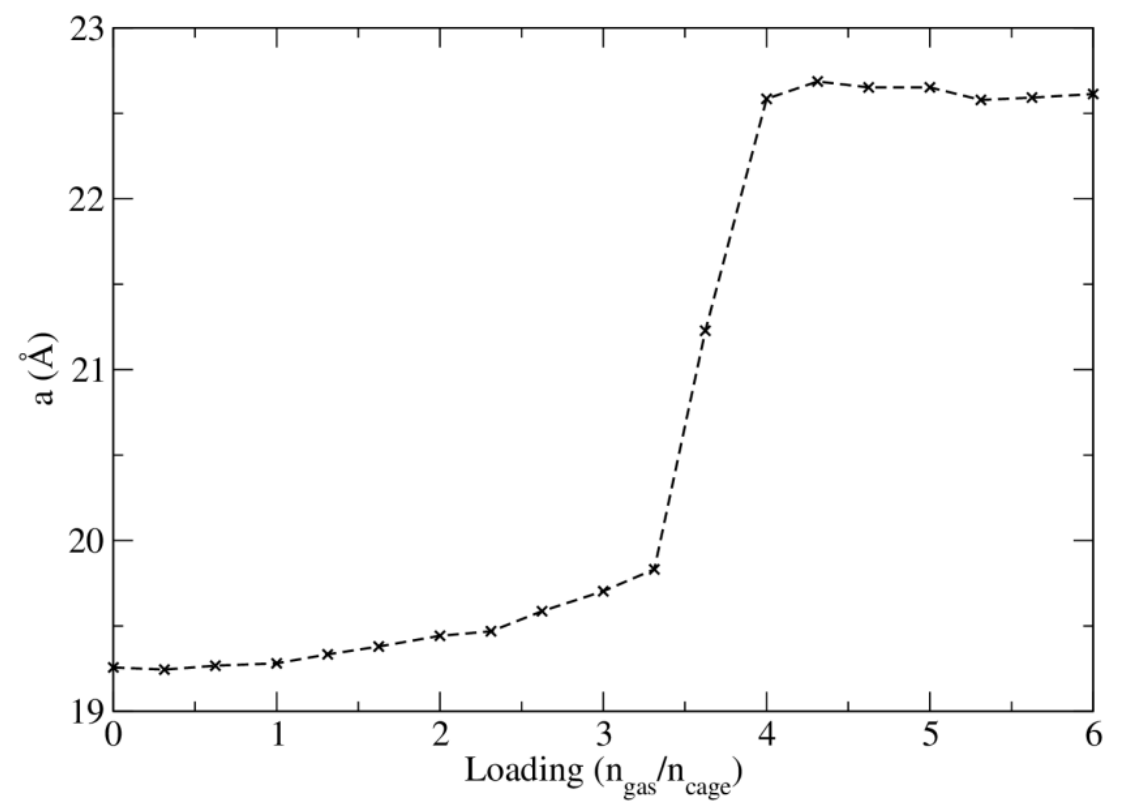

Figure S19. The elongation of the $a$ axis at $195 \mathrm{~K}$, plotted against the $\mathrm{CO}_{2}$ loading ratio.

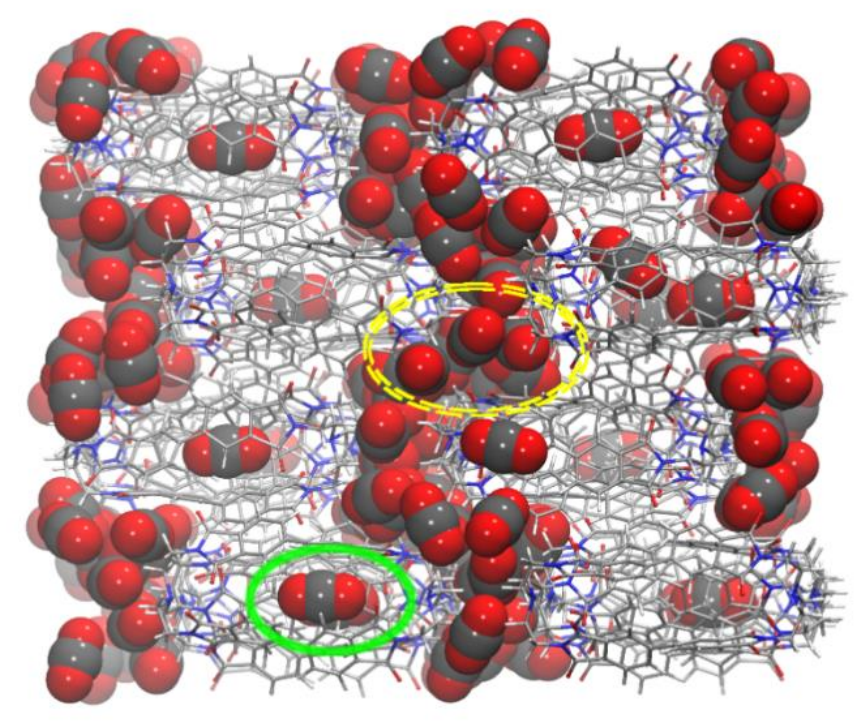

Figure S20. The simulated structure of NKPOC-1- $\gamma$ : inside the green solid circle is the intrinsic pore, and the yellow dashed circle is the extrinsic pore. 
a

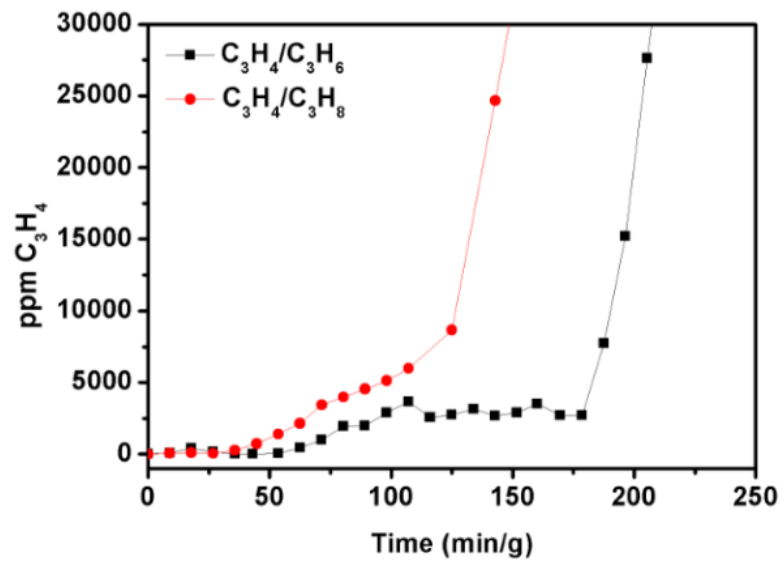

b

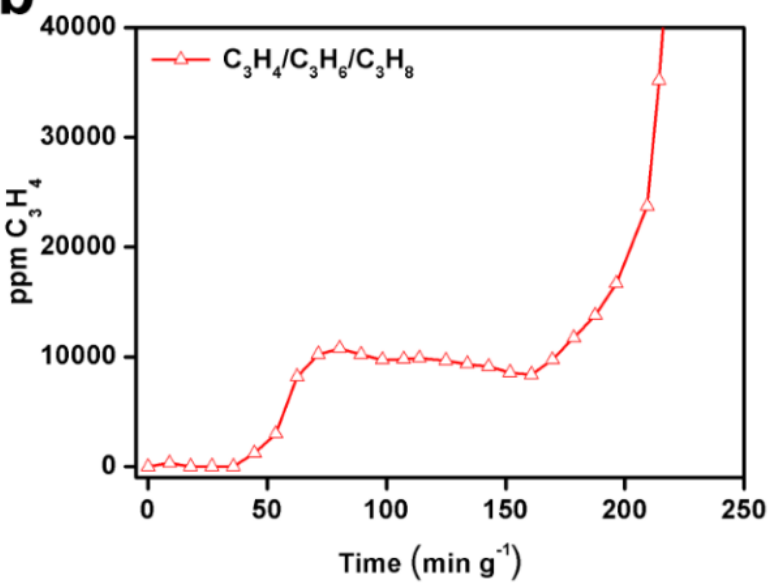

Figure S21. (a) Concentration of $\mathrm{C}_{3} \mathrm{H}_{4}$ in outlet: $<1700$ and $2833 \mathrm{ppm}$ for $2: 1(\mathrm{v} / \mathrm{v})$ binary $\mathrm{C}_{3} \mathrm{H}_{4} / \mathrm{C}_{3} \mathrm{H}_{6}$ and $\mathrm{C}_{3} \mathrm{H}_{4} / \mathrm{C}_{3} \mathrm{H}_{8}$ gas mixtures, respectively. (b) Concentration of $\mathrm{C}_{3} \mathrm{H}_{4}$ in outlet (<6229 ppm) for 2:1:1 (v/v/v) ternary $\mathrm{C}_{3} \mathrm{H}_{4} / \mathrm{C}_{3} \mathrm{H}_{6} / \mathrm{C}_{3} \mathrm{H}_{8}$ gas mixture.

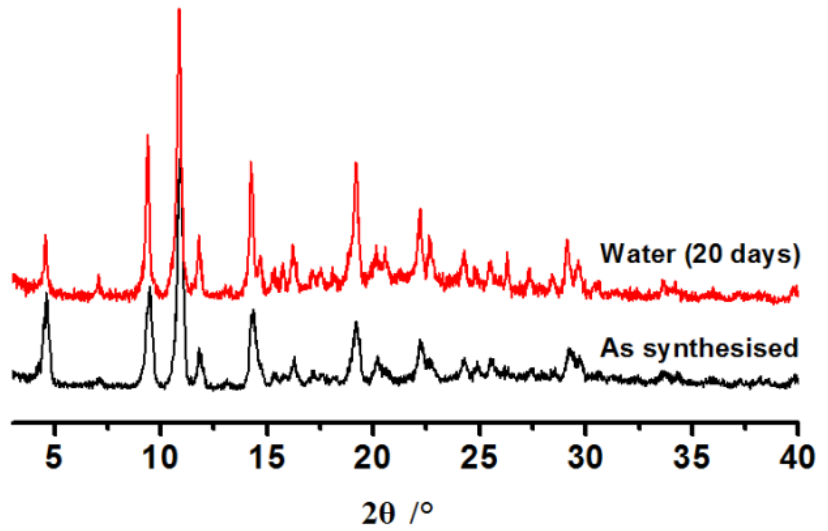

Figure S22. PXRD patterns of NKPOC-1- $\alpha$, as synthesized and after immersing into water 20 days.
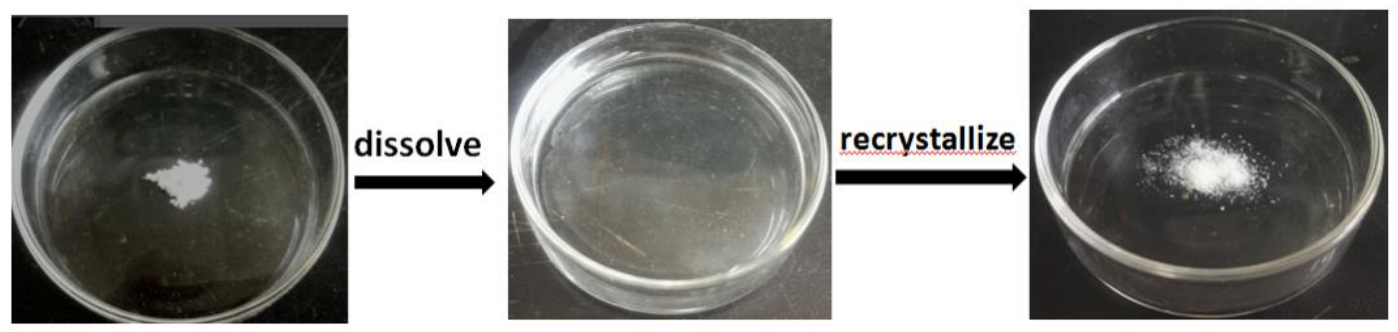

Figure S23. NKPOC-1 crystals were regenerated via recrystallization. 
Table S1. Reoptimized force field parameters: all modified force field parameters except the CHelpG charges are listed.

\begin{tabular}{|c|c|}
\hline Terms $^{\mathrm{a}}$ & Parameters \\
\hline$\sigma$ [carbonyl_C (opls_252) - carbonyl_O (opls_253)] & $0.290(\mathrm{~nm})$ \\
\hline$\varepsilon$ [carbonyl_C (opls_252) - carbonyl_O (opls_253)] & $0.6212923(\mathrm{~kJ} / \mathrm{mol})$ \\
\hline b0 (CT-NT) & $0.14624(\mathrm{~nm})$ \\
\hline $\mathrm{kb}(\mathrm{CT}-\mathrm{NT})$ & $\begin{array}{l}319657.6 \\
\left(\mathrm{~kJ} / \mathrm{mol} / \mathrm{nm}^{2}\right)\end{array}$ \\
\hline Scaling factor for dihedral (NT-CT-CT-N) ${ }^{b}$ & 0.3 \\
\hline Scaling factor for dihedral $(\mathrm{CA}-\mathrm{C} \text { !-C!-CA })^{\mathrm{c}}$ & 0.85 \\
\hline Scaling factor for $\sigma$ [Propyne $\mathrm{CH}_{3}$ (opls_135, opls_930)] & 0.92 \\
\hline $\begin{array}{l}\text { Scaling factor for } \varepsilon \text { between atoms in aromatic rings } \\
\text { (opls_145/145B/251) }\end{array}$ & 3.0 \\
\hline $\begin{array}{l}\text { Scaling factor for } \varepsilon \text { between atoms in } \mathrm{N}\left(\mathrm{CH}_{2} \mathrm{CH}_{3}\right) \text { header groups } \\
\text { (opls_902/908/911/257) }\end{array}$ & 1.8 \\
\hline
\end{tabular}

(a) all atom types are named following the standard OPLS-AA convention; (b) The original parameters are taken from the OPLS-AA NT-CT-CT-NT dihedral term, with the listed scaling factor applied; (c) The original parameters are taken from Dahlgren et al., ${ }^{16}$ with the listed scaling factor applied, this parameter is optimized separately to the B3LYP-D3/6-31G(d) di-phthalimide torsion profile.

Table S2. The CHelpG charges for the NKPOC-1 cage atoms.

\begin{tabular}{lll}
\hline Atom types & charges & Atom type explanation \\
\hline opls_145 & -0.03134 & Benzene C \\
opls_145B & 0.08406 & Biphenyl C1 \\
opls_146 & 0.11540 & Benzene H \\
opls_251 & -0.31576 & $\mathrm{~N}$ in imide \\
opls_252 & 0.56561 & $\mathrm{C}(=\mathrm{O})$ in imide \\
opls_253 & -0.49804 & $\mathrm{O}$ in imide \\
opls_257 & -0.01837 & $\mathrm{C}$ in $\mathrm{RCH}_{2}$ imide \\
opls_902 & -0.45092 & $\mathrm{~N}$ tertiary amines \\
opls_908 & 0.13499 & $\mathrm{CH}$ (N) tertiary aliphatic amines \\
opls_911 & 0.03642 & $\mathrm{H}(\mathrm{C})$ for C bonded to N in amine \\
\hline
\end{tabular}


Table S3. Crystal data and structure refinement for NKPOC-1- $\boldsymbol{\alpha}$ and NKPOC-1- $\boldsymbol{\beta}$.

\begin{tabular}{|c|c|c|}
\hline & NKPOC-1- $\alpha$ & NKPOC-1- $\beta$ \\
\hline Empirical formula & $\mathrm{C}_{60} \mathrm{H}_{44} \mathrm{~N}_{8} \mathrm{O}_{13}$ & $\mathrm{C}_{62} \mathrm{H}_{46} \mathrm{Cl}_{4} \mathrm{~N}_{8} \mathrm{O}_{12}$ \\
\hline CCDC number & 1904744 & 1904745 \\
\hline Space group & $P 21 / c$ & $P 21 / c$ \\
\hline Crystal system & monoclinic & monoclinic \\
\hline$a(\AA)$ & $18.6187(15)$ & $20.7759(7)$ \\
\hline$b(\stackrel{\AA}{)})$ & $15.7648(10)$ & $15.7504(6)$ \\
\hline$c(\stackrel{\AA}{)})$ & $17.9841(11)$ & $18.2205(6)$ \\
\hline$\alpha(\operatorname{deg})$ & 90 & 90 \\
\hline$\beta(\operatorname{deg})$ & $103.318(7)$ & $97.372(3)$ \\
\hline$\gamma(\operatorname{deg})$ & 90 & 90 \\
\hline$V(\AA)^{3}$ & $5136.7(6)$ & $5913.0(4)$ \\
\hline$Z$ & 4 & 4 \\
\hline Completeness & $99.7 \%$ & $99.6 \%$ \\
\hline $\operatorname{Dcalc}\left(\mathrm{g} / \mathrm{cm}^{3}\right)$ & 1.403 & 1.389 \\
\hline$\mu / m^{-1}$ & 0.101 & 0.271 \\
\hline Final $R$ indexes & $\begin{array}{l}\mathrm{R}_{1}=0.0908 \\
\mathrm{wR}_{2}=0.2233\end{array}$ & $\begin{array}{l}\mathrm{R}_{1}=0.0691 \\
\mathrm{wR}_{2}=0.1879\end{array}$ \\
\hline GoF & 1.039 & 1.058 \\
\hline
\end{tabular}

\section{References}

(1) Abraham, M. J.; Murtola, T.; Schulz, R.; Páll, S.; Smith, J. C.; Hess, B.; Lindahl, E. GROMACS: High Performance Molecular Simulations through Multi-Level Parallelism from Laptops to Supercomputers. SoftwareX 2015, 1-2, 19-25.

(2) Jorgensen, W. L.; Maxwell, D. S.; TiradoRives, J. Development and Testing of the OPLS All-Atom Force Field on Conformational Energetics and Properties of Organic Liquids. J. Am. Chem. Soc. 1996, 118, 11225-11236.

(3) Jorgensen, W. L.; Maxwell, D. S.; Tirado-Rives, J. Development and Testing of the OPLS All-Atom Force Field on Conformational Energetics and Properties of Organic Liquids. J. Am. Chem. Soc. 1996, 118 (45), 11225-11236.

(4) Kaminski, G. A.; Friesner, R. A.; Tirado-Rives, J.; Jorgensen, W. L. Evaluation and Reparametrization of the OPLS-AA Force Field for Proteins via Comparison with Accurate Quantum Chemical Calculations on Peptides. J. Phys. Chem. B 2001, 105 (28), 6474-6487.

(5) McDonald, N. A.; Jorgensen, W. L. Development of an All-Atom Force Field for Heterocycles. Properties of Liquid Pyrrole, Furan, Diazoles, and Oxazoles. J. Phys. Chem. B 1998, 102 (41), 8049-8059. 
(6) Jorgensen, W. L.; McDonald, N. A. Development of an All-Atom Force Field for Heterocycles. Properties of Liquid Pyridine and Diazenes. J. Mol. Struct. THEOCHEM 1998, $424(1), 145-155$.

(7) Rizzo, R. C.; Jorgensen, W. L. OPLS All-Atom Model for Amines: Resolution of the Amine Hydration Problem. J. Am. Chem. Soc. 1999, 121 (20), 4827-4836.

(8) Price, M. L. P.; Ostrovsky, D.; Jorgensen, W. L. Gas-Phase and Liquid-State Properties of Esters, Nitriles, and Nitro Compounds with the OPLS-AA Force Field. J. Comput. Chem. 2001, 22 (13), 1340-1352.

(9) Kresse, G.; Hafner, J. Ab Initio Molecular Dynamics for Liquid Metals. Phys. Rev. B 1993, $47(1), 558-561$.

(10) Kresse, G.; Hafner, J. Ab Initio Molecular-Dynamics Simulation of the Liquid-Metal-Amorphous-Semiconductor Transition in Germanium. Phys. Rev. B 1994, 49 (20), 14251-14269.

(11) Kresse, G.; Furthmüller, J. Efficient Iterative Schemes for Ab Initio Total-Energy Calculations Using a Plane-Wave Basis Set. Phys. Rev. B 1996, 54 (16), 11169-11186.

(12) Kresse, G.; Furthmüller, J. Efficiency of Ab-Initio Total Energy Calculations for Metals and Semiconductors Using a Plane-Wave Basis Set. Comput. Mater. Sci. 1996, 6 (1), 15-50.

(13) Klimeš, J.; Bowler, D. R.; Michaelides, A. Chemical Accuracy for the van Der Waals Density Functional. J. Phys. Condens. Matter Inst. Phys. J. 2010, 22 (2), 022201.

(14) Breneman, C. M.; Wiberg, K. B. Determining Atom-Centered Monopoles from Molecular Electrostatic Potentials. The Need for High Sampling Density in Formamide Conformational Analysis. J. Comput. Chem. 1990, 11 (3), 361-373.

(15) Lu, T.; Chen, F. Multiwfn: A Multifunctional Wavefunction Analyzer. J. Comput. Chem. 2011, 33 (5), 580-592.

(16) Dahlgren, M. K.; Schyman, P.; Tirado-Rives, J.; Jorgensen, W. L. Characterization of Biaryl Torsional Energetics and Its Treatment in OPLS All-Atom Force Fields. J. Chem. Inf. Model. 2013, 53 (5), 1191-1199. 